\title{
Assessment of Consumers' Awareness and Proposed Measures Against the Prevalence of Counterfeit Drugs in Developing Countries
}

Gideon Onuh ( $\sim$ gonuh@st.knust.edu.gh )

Kwame Nkrumah University of Science and Technology

Simon Karanja Hinga

Covenant University

Boniface Makori Nyamweya

University of Colombo

Atayero A. Aderemi

Covenant University

\section{Research Article}

Keywords: Counterfeit drugs, Active Pharmaceutical Ingredients (API), Antimicrobial Resistance (A.M.R.), Consumers' awareness

Posted Date: November 1st, 2021

DOI: https://doi.org/10.21203/rs.3.rs-998393/v1

License: (c) (i) This work is licensed under a Creative Commons Attribution 4.0 International License. Read Full License 


\section{Abstract}

Background: Counterfeit drugs have been reported as the primary cause of increased morbidity and drug resistance in developing countries. However, consumers' awareness of the prevalence of fake drugs in developing countries remains unknown.

Objectives: To assess consumers' awareness and the principal contributors of counterfeit drugs, propose measures to curb this menace in developing countries.

Method: Data were collected using a questionnaire with 24 questions bordering on consumer awareness and measures taken by health professionals in combating the prevalence of counterfeit drugs. All the questions were fully completed by participants and submitted online. The data were analyzed using both deductive and inductive approaches.

Results: It was observed that the level of awareness of counterfeit drugs among consumers varies across different countries. A high level of awareness was reported in countries with improved technology for combating substandard drugs, comparable to countries with lesser technology. The results show that pharmacy retailers and pharmaceutical industries are the major contributors to the prevalence of counterfeit medicines in developing countries. It was observed that consumers are exploring brand awareness and the physical appearance of drugs in the fight against counterfeit drugs.

Conclusion: This study assessed consumers' awareness of counterfeit drugs in selected developing countries and proposed measures that the government can implement in the fight against counterfeit drugs. These measures and findings may be appropriate in designing awareness programs and developing a framework for monitoring pharmaceutical production companies and supply chains.

\section{Background}

Over the years, there has been a growing trend in morbidity, mortality, and lack of trust in pharmaceutical products due to drug counterfeiting, especially in developing countries [1]. This has led to an increase in drug resistance and toxicity [2,3]. Many research papers and organizations have not clearly defined the word 'counterfeit drug' [4]. A drug containing the same active ingredient stated on the label can still be termed counterfeit if it is not packaged correctly using suitable packaging materials that can maintain its proper identity throughout its shelf life [5]. A drug can still be considered counterfeit when it contains the same, less or more than the active ingredients stated on the label [6]. Drug counterfeiting goes beyond the percentage content of the active ingredient in a pharmaceutical product [7]. It encompasses the entire process of drug production, from raw material sampling to intermediate specification and packaging [8]. According to [9], the prevalence of counterfeit drugs across the globe ranges from $1-50 \%$, with the developing countries experiencing a higher percentage of these statistics. This is because of the lowquality assessment and a lack of suitable equipment for drug monitoring [10]. Drug counterfeiting has drastically affected the pharmaceutical industries over the years [11]. The prevalence of drug counterfeiting has resulted in consumers lacking trust in many pharmaceutical products, resulting in a 
gradual decrease in demand [12]. The health implications of counterfeit drugs can be immediate or longterm [13]. When a drug contains more active ingredients in a formulation, it results in outright overdose consumption [14]. Drug overdose has been discovered to be the primary cause of increased morbidity and drug resistance [15].

There are reported counterfeit antimalaria drugs, such as beta-lactam, artemisinin derivatives, and chloroquine manufactured in Africa and Asia [16]. Including harmful substances (impurities) during production can also result in adverse effects and mortality [17]. Counterfeit drugs that contain an adequate amount of the active pharmaceutical ingredients but of inferior quality, commonly termed defective drug formulation, can cause bacterial resistance [18]. Counterfeiting the packaging of a pharmaceutical product can lead to product degradation and the formation of toxic compounds [19]. It is necessary to adhere to strict quality control measures in ensuring that pharmaceutical products maintain their true identity throughout shelf-life [20]. Here, we assess consumers' awareness, leading contributors and distributors of counterfeit drugs, also propose measures to curb the menace of counterfeit medicines in developing countries.

\section{Methods}

\section{Study Area}

The study was carried out across different countries of Africa and the South Pacific. Figure 1 shows regions where data was collected using online questionnaires. Participants were drawn from Ghana, Nigeria, South Africa, Laos, Kenya, and Pakistan. Respondents from Zambia, Zimbabwe, Togo, Tanzania, Rwanda, and DR. Congo partly participated in the study.

\section{Data Collection}

We carried out a general review before the assessment to ascertain awareness and reported counterfeit drug cases across targeted countries. A questionnaire with 24 questions bordering on consumers' awareness and measures taken by health professionals in combating the prevalence of counterfeit drugs was developed and hosted online through a google doc sheet. Data were collected from participants from July 2020 to September 2020. Participants included in the study were those that had used drugs for medical reasons. Those who had not used drugs for medical reasons were excluded from the research, and further data from them were not considered for this study. The assessment was applied directly to regulatory workers and consumers. Therefore, it can be stated that the quality of data collected is comparable across the questionnaires. The questions were comprehensive, and there was no conflict of interest between participants, individuals, and the authors. All the questions were fully completed by participants and submitted online. The questionnaire also contained open-ended questions for participants to share their views on pressing issues that needed to be addressed.

\section{Data Analysis}


The descriptive statistics were conducted at a 95\% confident interval limit using IBM SPSS Statistics 21 and a Data Analysis tool pack in Microsoft Excel 2016. The data were analyzed using both deductive and inductive approaches. The inductive analysis approach was by interpretation of raw data generated from open-ended questions. All statistical results of chi-square and t-test were significant at a $p$-value of $<0.05$.

\section{Results}

Table 1

Educational level of respondents

\begin{tabular}{|lll|}
\hline Category & Frequency & Percentage \\
\hline No formal education & 1 & $0 \%$ \\
Primary & - & $0 \%$ \\
Secondary & 13 & $4 \%$ \\
Tertiary education & 351 & $96 \%$ \\
& 365 & $100 \%$ \\
\hline
\end{tabular}

Three hundred and sixty-five individuals took part in the study. Of these, 237 respondents, representing $65 \%$, were males, while the remaining $128(35 \%)$ were females. Thus, most of the participants in the study were males. $5 \%$ of the respondents were between the ages of 14 and 20 years; $20 \%$ were between 35 and 50 years, while $34 \%$ were between 28 and 34 years. Individuals between 21-27 years accounted for the highest number of respondents in the study. As described in Table 1, it was observed that $96 \%$ of the respondents are in/have received tertiary education.

From the responses gotten from participants, as shown in Figure 2, 351 (96\%) admitted to having used drugs for medical reasons while 14 (4\%) showed 'No.' Those who offered to have used drugs were further asked whether the drugs were verified to be genuine or not. From the responses, 115 (29.6\%) showed 'Yes to always confirm the drugs,' $92(23.7 \%)$ indicated to 'sometimes confirm the genuineness of drugs.' In comparison, the remaining $158(36.7 \%)$ fall under the category of 'do not always confirm the genuineness of drugs.'

Most individuals with a secondary level of education showed to have always confirmed whether drugs are genuine, followed by four responses in the 'sometimes confirm' category. In comparison, the class 'No I don't confirm' has three answers. Those with tertiary education frequently confirmed drugs were 108, followed by 88 responses in the 'some time I confirm' group. However, 151 responses with tertiary educational education do not always check the genuineness of drugs. Having established that many respondents affirmed that they sometimes confirm whether the drugs they consume are genuine, it was essential to test whether one's ability to detect counterfeit medicines depends on educational level. The following hypotheses were planned: Ho: ability to confirm whether drugs consumed are genuine is 
independent of one's educational background. $\mathrm{H} 1$ : The ability to verify if drugs consumed are genuine depends on one's academic experience at 0.05 significant level. The calculated p-value of 0.594 was greater than 0.05; therefore, we cannot reject the null hypothesis and conclude that one's ability always to confirm whether the drugs consumed are genuine is independent of educational background. An individual could consume a particular drug for a long time, and because of constant usage, many consumers cannot confirm the originality of such medications.

Table 2

Counterfeit Drugs Awareness by Country

\begin{tabular}{|c|c|c|c|c|c|c|}
\hline & & \multicolumn{4}{|c|}{ Level of Awareness of Counterfeit drugs } & \multirow[t]{2}{*}{ Total } \\
\hline & & Yes & No & Maybe, not sure. & Not at all & \\
\hline \multirow[t]{6}{*}{ Country of Origin } & Nigeria & 149 & 12 & 9 & 3 & 173 \\
\hline & Ghana & 21 & 12 & 4 & 1 & 38 \\
\hline & Kenya & 24 & 4 & 30 & - & 58 \\
\hline & Pakistan & 11 & 1 & 1 & 1 & 14 \\
\hline & Laos & 5 & - & 1 & - & 6 \\
\hline & South Africa & 1 & - & 1 & - & 2 \\
\hline
\end{tabular}

The study also explores consumers' awareness of counterfeit drugs in countries under investigation, as shown in Table 2. We performed a correlation test to determine whether there is a linear relationship between the country of origin and awareness of counterfeit drugs; there is a strong positive linear association between country of origin and counterfeit drugs with a p-value $<0.01$ significant level. The result was further supported by the Chi-Square of independence testing following this hypothesis, Ho: the awareness of counterfeit drugs is independent of country of origin, $\mathrm{H} 1$ : the awareness of counterfeit medicines depends on the country of origin. The result implies that the awareness of counterfeit drugs depends on the country of origin ( $p$. value $=0.000<0.05)$. 
Table 3

Effect of Counterfeit Drugs on Consumers

\begin{tabular}{|llc|}
\hline Variables & Frequency & Percentage \\
\hline Yes & $\begin{array}{l}\text { Consumed/purchased counterfeit } \\
\text { drugs Unknowingly }\end{array}$ & 15.7 \\
No & 61 & 23.7 \\
I am not Sure & 106 & 51.0 \\
& 198 & 7 \\
\hline Given by a doctor & Source of the counterfeit drug \\
\hline $\begin{array}{l}\text { Purchased a prescribed drug from the } \\
\text { pharmacy }\end{array}$ & 27 & 28.9 \\
\hline $\begin{array}{l}\text { Purchased an unprescribed drug over the } \\
\text { counter }\end{array}$ & 112 & 29.6 \\
Other & 115 & 21.9 \\
\hline Nes & 85 & Experience a medical problem caused \\
\hline No & 68 & 19.1 \\
\hline
\end{tabular}

Table 3 describes consumers' experiences after taking counterfeit drugs and the sources of purchase. $15.7 \%$ of consumers admitted to having purchased counterfeit drugs unknowingly, while $51.01 \%$ were not sure whether to have purchased counterfeit drugs unknowingly. Out of the $15.7 \%$ who claimed to have purchased counterfeit drugs, $29.6 \%$ indicated having purchased it as unprescribed drugs over the counter, $28.9 \%$ purchased it as prescribed drugs from the pharmacy, and $21.9 \%$ can not explain how it was purchased. Respondents who admitted to having purchased and consumed counterfeit drugs were further asked if they experienced any medical challenge after taking them. $80.8 \%$ showed not to experienced any side effect as an aftermath of the drug consumption, while $19.1 \%$ agreed to have experienced several side effects afterward.

\section{Discussion}

The study shows that Nigeria recorded the highest awareness of counterfeit drugs with (149 responses). Kenya (24), Ghana (21), Pakistan (11), Laos (5), and South Africa (1) followed this. A lot of factors could influence the variation in awareness among the countries. The high level of awareness recorded in Nigeria could be related to the country's population [21]. The level of awareness of counterfeit drugs was 
observed to vary from country to country. In Nigeria, for instance, the National Agency for Food and Drug Administration Control (NAFDAC) implemented a short code in 2015, which allows consumers to confirm the authenticity of a drug via mobile phones [22]. It provides first-hand information about the drug to consumers at the point of purchase. This technology might be the primary reason behinds the high level of awareness among consumers in Nigeria. There is a decrease in awareness of counterfeit drugs among consumers in Ghana; most consumers depend on the regulatory body to certify drugs produced and imported into the country. A mixed reaction was recorded between Kenyan consumers; most consumers are not sure of counterfeit medicines on the market. Pakistan recorded a high level of unawareness of counterfeit drugs by consumers. The following results were the awareness of fake medicines in the locality and their significant contributors to their existence. $73 \%$ of the respondents believed that manufacturing companies and retailers are the major contributors to counterfeit drugs in their country. The remaining respondents blamed it on the government and the health professionals. Since pharmaceutical industries import or produce most drugs distributed locally, it is believed that they are the major contributors to the existence of counterfeit medicines in many countries to generate high returns on investment. Government and health professionals were also considered to play a significant role in the prevalence of fake drugs in developing countries. They primarily handle the appointment of qualified health professionals who must ensure that every medicine, whether imported or locally manufactured, meets the acceptable standard before approval. For instance, the government-appointed FDA and NAFDAC officials monitor drugs in Ghana and Nigeria, respectively [23]. However, the failure of these agencies to apprehend faulted pharmaceutical companies through government interventions via autocracy or corrupt means would cause the circulation of such counterfeit drugs in the market [24]. Retailers are not responsible for monitoring drugs but could be responsible for the circulation of fake drugs for making profits [25]. Most of the respondents, $51 \%$, were unsure whether they had consumed or purchased counterfeit drugs. This could result from brand awareness, thus making it difficult to differentiate the original prescription from the fake counterpart [26].

It was observed that most consumers purchase counterfeit drugs through unprescribed over-the-counter purchases. It was discovered that doctors contribute little to the consumption of counterfeit medicines by patients. Having looked carefully at the source of counterfeit drugs, $19.1 \%$ of the respondents confirmed to have experienced medical complications resulting from counterfeit drugs. Some of these medical problems were due to drug-drug interaction, wrong medications, self medications, etc. The remaining $80.9 \%$ showed not to have suffered any medical issues, probably because the effects of the drugs were not immediate.

\section{PROPOSED MEASURES TO CURB COUNTERFEIT DRUGS IN DEVELOPING COUNTRIES}

We propose several ways to prevent the proliferation and control of substandard and falsified medical products, promoting access to affordable, safe, productive, and quality medicines.

\section{A Comprehensive Legal Framework}


The first proposed intervention is developing a comprehensive legal framework that guides the production and selling of medicinal products, the establishment of institutions that enforce strict legal penalties on the offenders. The legal framework should regulate the production and marketing of medicinal products and ensure that every pharmacy store, retailer, or wholesaler is licensed or subject to a specific marketing authorization before being allowed to sell or distribute medicinal products. All medicinal products, both pharmaceutical and herbal, must be granted marketing authorization by a relevant regulatory authority in that country. The marketing authorization procedure should ensure that the therapeutic efficacy outweighs the potential side effects of such medication. Strict regulations should be imposed on the procurement of licenses to establish pharmaceutical companies, pharmacy outlets, importation, exportation, storage, distribution, marketing or advertising, sale, prescription, pharmaceutical care, and the use of medicinal products. It is noteworthy that a more significant percentage of counterfeit drugs are sold via the internet [27]. Therefore, legislating against any online sale of drugs will make it hard for fake drug dealers to navigate this illegal business. Besides the aforementioned legal measures, pharmaceutical companies, wholesalers, and pharmacy outlets should be subjected to periodic inspections by the relevant regulatory authorities in the country. A more workable intervention would be to institute a global database for substandard/falsified medicinal products. When a healthcare worker or consumer detects a counterfeit drug, a real-time report should be available to the regulatory body. The database can also be centralized. If it receives information concerning a counterfeit drug in circulation, it can readily disseminate an alert to the country or region that is likely to be at higher risk.

\section{Supply Chain Integrity}

Using technology to ensure supply chain integrity is an excellent measure to curb counterfeit drugs in developing countries. This is possible through developing a tamper-proof authenticity band system on drug packaging [28]. These safety features can be visually recognizable, such as barcodes and holograms or hidden identification marks on the packaging. For example, suppose it is a barcode when scanned; it should provide details of the drug, such as the manufacturer's name, the manufacturing date, the expiry date, the active ingredients, and the dosage, among other details. The safety feature should not be prone to re-use. It should provide a means to trace the drug's path and provide a means of reimbursement, probably by insurance companies. Through such a technology, it will be possible to know the authenticity of any drug and decimate the distribution of counterfeit medicines across borders.

\section{Education and Awareness}

Another way to curb the challenges of counterfeit drugs is by providing the consumers with accurate and balanced information on the risks of substandard and falsified medicines, how to avoid them, how to identify them, and how to report to relevant authorities. These will help consumers to move from informal markets to safer outlets to source for their medications. Relevant government agencies should provide effective reporting systems such that healthcare providers and consumers can easily report suspicious medical products. Investing in public awareness will enable consumers to be more alert and informed about the prevalence of counterfeit drugs and the need to adhere to preventive measures. 


\section{Conclusion}

The flourishing business of counterfeit drugs at the expense of consumers' health and well-being in developing countries requires a high level of awareness. It is paramount for the government to invest in human resources and the technology needed to fight this menace. The regulatory bodies should closely monitor and regulate pharmaceutical industries and retailers to minimize the distribution of counterfeit drugs in the market. We all have the responsibility to educate the populace about the danger associated with counterfeit medicines. Proper awareness will increase consumers' knowledge of fake drugs, and adherence to safety measures will weaken the distribution of counterfeit drugs within our localities.

\section{Declarations}

\section{Ethics approval and consent to participate}

The committee on human research publication and ethics, School of Medical Sciences, Kwame Nkrumah University of Science and Technology Kumasi, Ghana, waived the requirements for an ethical clearance certificate for this study. All the survey protocol for involving human data was in accordance with the guidelines of the 2013 Declaration of Helsinki Code, as revised by [29]. The first page of the questionnaire contains the participant consent section, which permits the participants to know enough about the research for voluntary participation. Information was anonymously received from participants without names and cannot be traced to them in any way. All the participants provided infromed consent including parental consent for minors below age 16 years.

\section{Consent for publication}

Not Applicable

\section{Available Data and Materials}

We fully reference all research articles used in this study. Raw data associated with this article is deposited on the repository and can be accessed on Mendeley data as DOI: 10.17632/n6zk3dp8fy. 1

\section{Competing Interests}

The authors declare that they have no known competing financial interests or personal relationships which have, or could be perceived to have, influenced the work reported in this article.

\section{Funding}

The Article Processing Cost was covered by the Centre for Research, Innovation and Discovery Covenant University, Ota, Nigeria

\section{Author's Contribution}


SKH and BMN conceived and designed the questionaries. GO analyzed the data and drafted the manuscript. AAA critically reviewed and accepted the final content of the manuscript. SKH and BMN systematically revised and reviewed the manuscript.

\section{Acknowledgement}

This study was supported by the Queen Elizabeth Commonwealth Scholarship (QECS) under the SDG-3 (Good Health and Well-Being) research group, Association of Commonwealth Universities (London, WC1H9HF).

\section{References}

1. Newton P. N., Green M. D., Fernández F. M., Day N. P. J. and White N. J. “Counterfeit anti-infective drugs," vol. 6, no.4, September, 2006.

2. Shefet-Carasso L. and Benhar I. "Antibody-targeted drugs and drug resistance; Challenges and solutions", Drug Resistance Updates, vol. 18, pp. 36-46, 2015. Available: 10.1016/j.drup.2014.11.001.

3. Erhun W., Babalola O. and M.O M. "Drug Regulation and Control in Nigeria: the Challenge of Counterfeit Drugs", World Health \& Population, vol. 4, no. 2, 2013. Available: 10.12927/whp..17597.

4. Foon K. "Clearly defined response criteria evaluating treatment of CLL patients in clinical research trials", Blood, vol. 116, no. 10, pp. 1817-1817, 2010. Available: 10.1182/blood-2010-03-274035.

5. Yusufu D., Wang C. and Mills A. "Evaluation of an 'After Opening Freshness (AOF)' label for packaged ham", Food Packaging and Shelf Life, vol. 17, pp. 107-113, 2018. Available: 10.1016/j.fpsl.2018.06.002.

6. Reidenberg M. M., Conner B. A. and York N. "clinical Counterfeit and substandard drugs," vol. 69, no. 4, pp. 189-193, 2001.

7. Gollapalli R., et al., "Identification of an Adduct Impurity of an Active Pharmaceutical Ingredient and a Leachable in an Ophthalmic Drug Product Using LC-QTOF", Journal of Pharmaceutical Sciences, vol. 108, no. 10, pp. 3187-3193, 2019. Available: 10.1016/j.xphs.2019.06.009.

8. Mitka M. "Curbing Counterfeit Drug Sales", JAMA, vol. 311, no. 14, p. 1389, 2014. Available: 10.1001/jama.2014.3716.

9. Paolo S. Ã. O. "Epidemic of counterfeit drugs causes concern in Brazil," vol. 352, p. 1998, 1998

10. Mpharm P. C. K., et al., "The quality of essential antimicrobial and antimalarial drugs marketed in Rwanda and Tanzania: influence of tropical storage conditions on in vitro dissolution," pp. 331-338, 2004.

11. Holzgrabe U. and Malet-Martino M. "Analytical challenges in drug counterfeiting and falsificationThe NMR approach", Journal of Pharmaceutical and Biomedical Analysis, vol. 55, no. 4, pp. 679-687, 2011. Available: 10.1016/j.jpba.2010.12.017.

12. Степаненко C. "Study of products counterfeiting protection technologies on the ukrainian pharmaceutical market", ScienceRise, vol. 10, no. 415, p. 41, 2015. Available: 10.15587/2313- 
8416.2015.51989.

13. Becvarova I. and Buechner-Maxwell V. "Feeding the foal for immediate and long-term health", Equine Veterinary Journal, vol. 44, pp. 149-156, 2012. Available: 10.1111/j.2042-3306.2011.00522.x.

14. Wollowitz S. "Managing high-potency active pharmaceutical ingredients-A drug sponsor's guide", Drug Development Research, vol. 71, no. 7, pp. 420-428, 2010. Available: 10.1002/ddr.20385.

15. Kelesidis T. and Falagas E. "Substandard / Counterfeit Antimicrobial Drugs," vol. 28, no. 2, pp. 443464, 2015.

16. Ernst E. "Counterfeit drugs," Perfusion, vol. 18, no. 2, p. 49, 2005.

17. Nielsen M. and Jiang S. "Can cyanotoxins penetrate human skin during water recreation to cause negative health effects?", Harmful Algae, vol. 98, p. 101872, 2020. Available:

10.1016/j.hal.2020.101872.

18. Rozendaal J. "Fake antimalaria drugs in Sizing up research For personal use only . Reproduce with permission from The Lancet Publishing Group .," Lancet, vol. 357, pp. 2001-2001, 2001.

19. Spink J. "Product fraud and product counterfeiting as a source of terrorist financing", Security Journal, vol. 30, no. 2, pp. 640-645, 2017. Available: 10.1057/sj.2014.46.

20. Sakkal E., Bitar Y. and Trefi S. "Quality control of the active Pharmaceutical ingredients of some Pharmaceutical products prior the termination of their shelf life", Research Journal of Pharmacy and Technology, vol. 12, no. 12, p. 6111, 2019. Available: 10.5958/0974-360x.2019.01062.x.

21. Gellad W., Huskamp H., Phillips K. and Haas J. "How the New Medicare Drug Benefit Could Affect Vulnerable Populations", Health Affairs, vol. 25, no. 1, pp. 248-255, 2006. Available:

10.1377/hlthaff.25.1.248.

22. Igbokwe-lbeto C. "Re-inventing Nigeria's Public Sector: A Review of National Agency for Food, Drug Administration and Control (NAFDAC)", Africa's Public Service Delivery and Performance Review, vol. 3, no. 2, p. 183, 2015. Available: 10.4102/apsdpr.v3i2.85.

23. Wogu J., Omaka-Amari L., Ugwu U., Ugwuoke J. and Agu M. "Influence of NAFDAC Mobile Drugs Authentication Service on the Use of Fake Drugs Among Consumers in Southeast Nigeria", Global Journal of Health Science, vol. 11, no. 5, p. 87, 2019. Available: 10.5539/gjhs.v11n5p87.

24. Labaran M. and Hamma-Adama M. "The Nigerian Pharmaceutical Supply Chain: Blockchain Adoption, Counterfeit Drugs and Successful Deployment of COVID-19 Vaccine in Nigeria", Journal of Scientific Research and Reports, pp. 20-36, 2021. Available: 10.9734/jsrr/2021/v27i230356.

25. Erhun W., Babalola O. and MO M. "Drug Regulation and Control in Nigeria: the Challenge of Counterfeit Drugs", World Health \& Population, vol. 4, no. 2, 2013. Available: 10.12927/whp..17597.

26. Ameliawaty R. and Halilah I. "Pengaruh Brand Awareness terhadap Consumer Decision Making The Influence of Brand Awareness to Consumer Decision Making", Jurnal Riset Bisnis dan Investasi, vol. 3, no. 2, p. 63, 2018. Available: 10.35697/jrbi.v3i2.934.

27. Dean J., Klep R. and Aquilina J. "Counterfeit dapoxetine sold on the Internet contains undisclosed sildenafil", International Journal of Clinical Practice, vol. 64, no. 9, pp. 1319-1322, 2010. Available: 
10.1111/j.1742-1241.2010.02436.x.

28. Shukla A., Gupta A., Jha M. and Chaudhary S. "Tamperproof Evidence with Blockchain", SSRN Electronic Journal, 2019. Available: 10.2139/ssrn.3387832.

29. Nicogossian A., Kloiber O. and Stabile B. "The Revised World Medical Association's Declaration of Helsinki 2013: Enhancing the Protection of Human Research Subjects and Empowering Ethics Review Committees", World Medical \& Health Policy, vol. 6, no. 1, pp. 1-3, 2014. Available: 10.1002/wmh3.79.

\section{Figures}

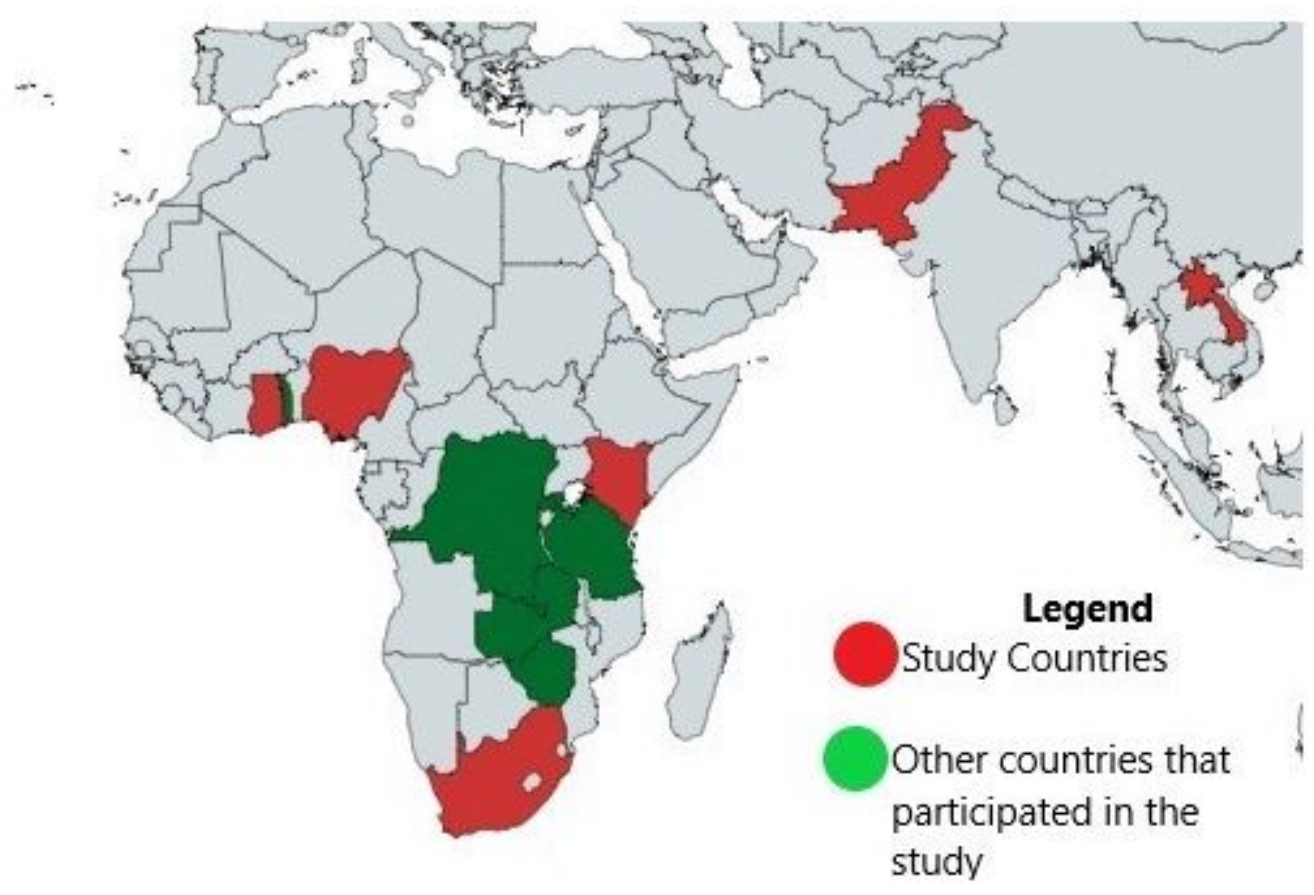

Figure 1

Study Countries 


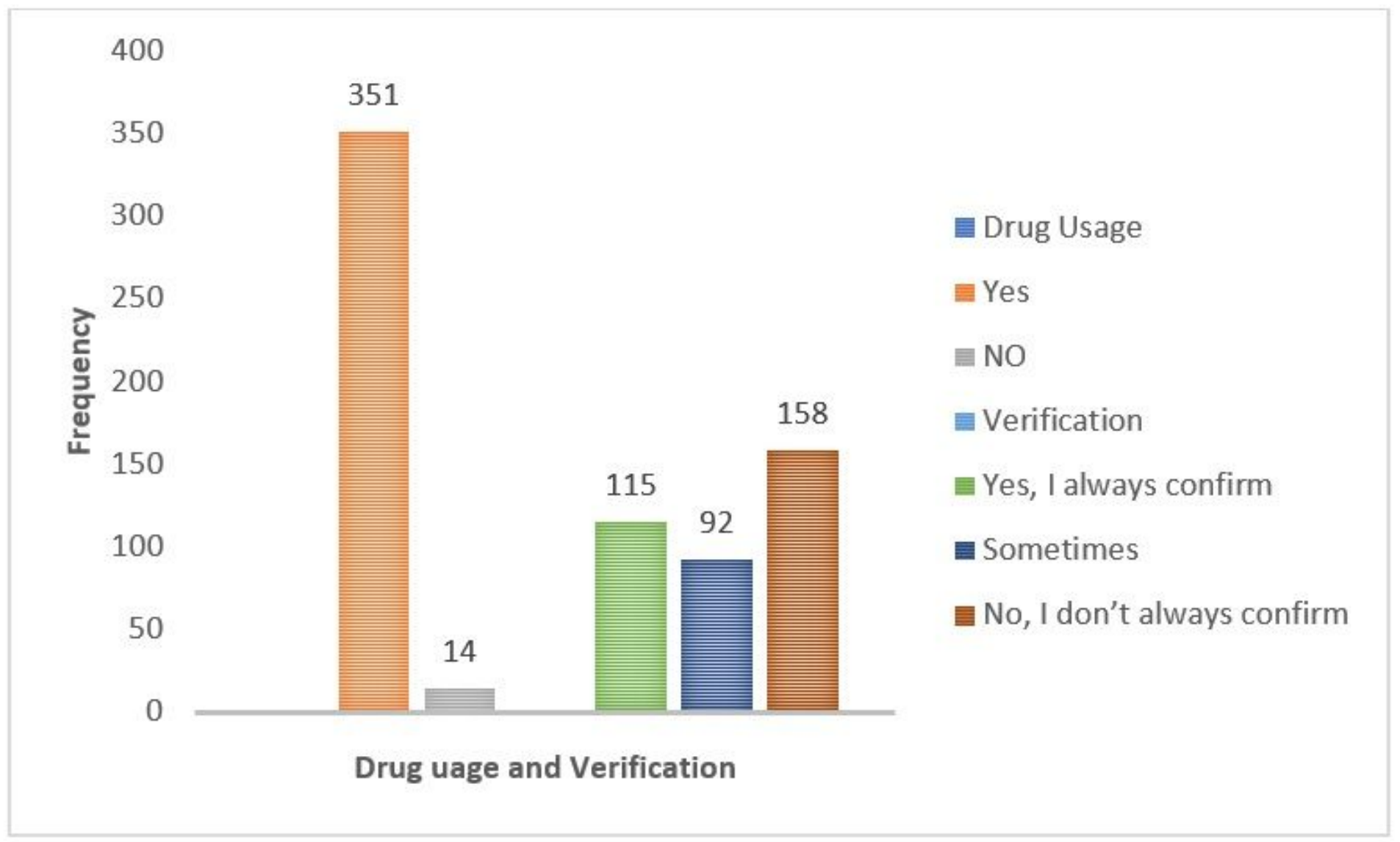

Figure 2

Drugs Usage and Verification 